\title{
CORROSION PRODUCT ANALYSIS OF CORROSION RESISTANT ANCIENT INDIAN IRON
}

\author{
A.V. RAMESH KUMAR ${ }^{\mathrm{a}}$ and R. BALASUBRAMANIAM ${ }^{\mathrm{b} *}$ \\ ${ }^{a}$ Electrochemistry and Corrosion Division, Defense Materials and Stores Research Establishment (DMSRDE), \\ 208013 Kanpur, India \\ ${ }^{b}$ Department of Materials and Metallurgical Engineering, Indian Institute of Technology, 208016 Kanpur, India
}

\begin{abstract}
The corrosion product formed on an ancient 1500-year old non-corroded iron clamp was studied by X-ray diffraction (XRD), Fourier transform infrared spectroscopy (FTIR) and Mössbauer spectroscopy. The iron possessed a non-uniform grain structure with dispersed second phase particles. Microscopy indicated that rust present on the surface was composed of an adherent and compact inner layer and a loose outer layer. Enrichment of $\mathrm{P}$ was observed at the metal-scale interface and in the inner rust layer. XRD indicated that the rust was amorphous in nature. The FTIR spectrum provided that the major constituents of the scale were $\alpha-, \gamma-$, $\delta-\mathrm{FeOOH}$ and $\mathrm{FePO}_{4} \cdot 2 \mathrm{H}_{2} \mathrm{O}$. Mösbauer studies further indicated that these constituents were present in a very fine form, confirming the results obtained by XRD. The presence of a magnetic oxide with a lower field strength than that of magnetite was also identified. The process of protective rust formation on the ancient Indian iron has been elucidated based on the results of the study. Initially, the corrosion rate of the iron is high due to the presence of the slag particles which results in enhancement of the $\mathrm{P}$ content in the surface. In the presence of $\mathrm{P}$, the formation of a protective amorphous compact layer of $\delta-\mathrm{FeOOH}$ is catalyzed and this confers corrosion resistance. The conversion of $\mathrm{FeOOH}$ to magnetite is also indicated and this would further improve the corrosion resistance. Another factor aiding corrosion resistance is the formation of iron phosphates which would lower the rate of corrosion. (C) 1998 Elsevier Science Ltd. All rights reserved
\end{abstract}

Keywords: A. ancient Indian iron, Delhi iron pillar, C. rust characterization, mechanism of protection

\section{INTRODUCTION}

The Delhi iron pillar is testimony to the high level of skill achieved by the ancient Indian iron smiths in the extraction and processing of iron. The iron pillar at Delhi has attracted the attention of archaeologists and corrosion technologists as it has withstood corrosion for the last 1600 years. Several theories which have been proposed to explain its superior corrosion resistance can be broadly be classified into two categories: the environmental ${ }^{1-3}$ and material ${ }^{4-7}$ theories. The proponents of the environment theory state that the mild climate of Delhi is responsible for the corrosion resistance of the Delhi iron pillar as it is known that the relative humidity at Delhi does not exceed $70 \%$ for significant periods of time in the year, ${ }^{2}$ which therefore results in very mild corrosion of the pillar. On the other hand, several investigators have stressed the importance of the material of construction as

* To whom correspondence should be sent.

Manuscript received 20 November 1997. 
the primary cause for its corrosion resistance. The ideas proposed in this regard are the relatively pure composition of the iron used, ${ }^{4}$ presence of phosphorus and absence of S/Mn in the iron, ${ }^{5}$ its slag enveloped metal grain structure, ${ }^{3}$ and passivity enhancement in the presence of slag particles. ${ }^{6,7}$ Other theories to explain the corrosion resistance are also to be found in the literature like the mass metal effect, ${ }^{3}$ initial exposure to an alkaline and ammonical environment, ${ }^{2}$ residual stresses resulting from the surface finishing operation, ${ }^{8}$ freedom from sulphur contamination both in the metal and in the air, ${ }^{8}$ and surface coatings provided to the pillar after manufacture (barfing ${ }^{9}$ and slag coating ${ }^{10}$ ) and during use (coating with clarified butter). ${ }^{3}$ That the material of construction may be the important factor in determining the corrosion resistance of ancient Indian iron is attested by the presence of ancient massive iron objects located in areas where the relative humidity is high for significant periods in the year (for example, the iron beams in the Surya temple at Konarak in coastal Orissa and the iron pillar at Mookambika temple at Kollur situated in the Kodachadri Hills on the western coast). It is, therefore, obvious that the ancient Indians, especially from the time of the Guptas (300-500AD), produced iron that was capable of withstanding corrosion. This is primarily due to the high $\mathrm{P}$ content of the iron produced during these times. The addition of $\mathrm{P}$ was intentional as iron produced during earlier times do not show the presence of $\mathrm{P}$ in them.

In order to understand the corrosion resistance of the Delhi pillar, it would have been ideal to study samples from the Delhi iron pillar. However, this is not possible as specimens from the Delhi iron pillar are not available currently. In view of this, it was deceived to obtained iron produced during the time of the Guptas, the time period in which the Delhi iron pillar was constructed. It is well known that several advances were made in iron technology (extraction and processing) during the time of the Guptas, the most notable example being the Delhi iron pillar. ${ }^{11-13}$ It is well established that iron bowels were utilized for clamping stone blocks used in the construction of Gupta temples. ${ }^{14}$ Therefore, a trip was made to a remote area in Madhya Pradesh in central India to a place called Eran, which was formerly the imperial capital of the Guptas (then called Eirakina), especially from the latter part of the 5th century. There lies at Eran a ruined temple structure where iron clamps, used for holding together blocks of stone, could be located. Some of the iron clamps were found to be in an excellent state of preservation. A non-corroded iron clamp, exhibiting a thin adherent oxide layer, was removed from one of the stone blocks.

The aim of the present study is to understand the nature of corrosion product formed on this corrosion resistant ancient Indian iron. The present study should also provide valuable insights into the corrosion resistance of the Delhi pillar iron as both these irons were produced during the same time and possess similar microstructures. ${ }^{15}$

\section{EXPERIMENTAL PROCEDURE}

The non-corroded iron clamp was detached from one of the stone blocks in the ruined Gupta temple at Eran, Madhya Pradesh. Inscriptions in the temple site indicate that the temple was constructed during the later half of the fifth century. ${ }^{16}$ Therefore, the iron clamp obtained was at least 1500 years old.

Several specimens were sectioned from the iron clamp. One of the cross sections was used to analyze the microstructures of the metal and rust using a JEOL JSM840A scanning electron microscope (SEM). The compositions of the material and the entrapped slag particles in the iron were obtained at several locations on the cross section with a JEOL 
JXA8600 electron probe microanalyzer (EPMA). The phosphorous content of the iron was also determined by wet chemical analysis. The nature of rust on the non-corroded iron was analyzed initially by X-ray diffraction (XRD) with a Rich Seifert 2000D diffractometer using $\mathrm{Cu} \mathrm{K} \alpha$ radiation. In order to further understand the constituents of the scale, the rust was analyzed by Fourier transform infrared (FTIR) and Mössbauer spectroscopy. For this purpose, some of the rust was removed from the clamp and finely powdered. The finely powdered rust was sandwiched between a cellophane tape and mounted on a sample holder of a Mössbauer spectrometer in transmission geometry. The spectrometer controller model was S-600 of Austin Science Associates (ASA), USA with linear motor of ASA, USA which was coupled with a Norland Ortec Multichannel analyzer and proportional counter $(\mathrm{Kr}$ at $1 \mathrm{~atm}$ and $3 \% \mathrm{CO}_{2}$ ) manufactured by Ranger Corporation, USA and these were used to count the $14.4 \mathrm{KeV} \gamma$-ray. The Mössbauer spectrum was recorded in a fly back mode at room temperature in 1024 channels which gives a single spectrum. The Mössbauer data was fitted to Lorentzian approximation using $\mathrm{mm} /$ sirus v.2.7 Mössbauer handling program. The Fourier transform infrared (FTIR) spectrum were recorded at room temperature using a Nicolet Magna 750 Series 2, USA FTIR system. Rust samples were pressed in discs using spectroscopically pure $\mathrm{KBr}$.

\section{RESULTS AND DISCUSSION}

Structure

On visual observation, the iron clamp contained a black adherent rust layer, which could not be chipped off the iron substrate easily. Salient features of the microstructure would be first discussed. The iron possessed a non-uniform grain structure (Fig. 1(a)). The surface regions of the iron exhibited a grain structure that was essentially ferritic. The grain size in this location was approximately about $50 \mu \mathrm{m}$. On the other hand, the grain structure in the inner regions of the iron clamp, far away from the surface, contained a higher amount of carbon. The structure in this region consisted of small pearlite colonies located at the grain boundaries of the ferrite grains. The grain size of ferrite in the central region was about $10 \mu \mathrm{m}$. Moreover, second phase particles were distributed unevenly throughout the structure. The transverse section also exhibited a non-uniform structure, with the surface regions rich in ferrite and the central regions consisting of both pearlite and ferrite. The finer grains at the center possessed a grain size of $10 \mu \mathrm{m}$ and the grain size near the surface regions was approximately $75 \mu \mathrm{m}$. It was also observed that the second phase particles were present in elongated form in the transverse section (Fig. 1(b)). The elongated nature of the slag particles could be due to the working operation employed to fabricate this clamp. This is a typical characteristic of wrought ancient Indian iron.

As noted above, second phase particles (slag inclusions and unreduced $\mathrm{FeO}$ ) were distributed unevenly in the matrix. Figure 1(c) provides an example of a second phase particle that is relatively large in size. It was generally observed that the interface between the second phase particle and the matrix was separated. The second-phase particles were compositionally analyzed. Most of the dispersoids were slag particles which had the composition of $\mathrm{Fe}_{2} \mathrm{SiO}_{4}$ (fayelite) while some of the second phase particles were unreduced $\mathrm{FeO}$. These constituents result due to the extraction technique used for obtaining iron. ${ }^{11-13}$ Iron was extracted by solid state reduction of iron ore in the presence of charcoal. Once the reduction was complete, the iron produced was squeezed to 

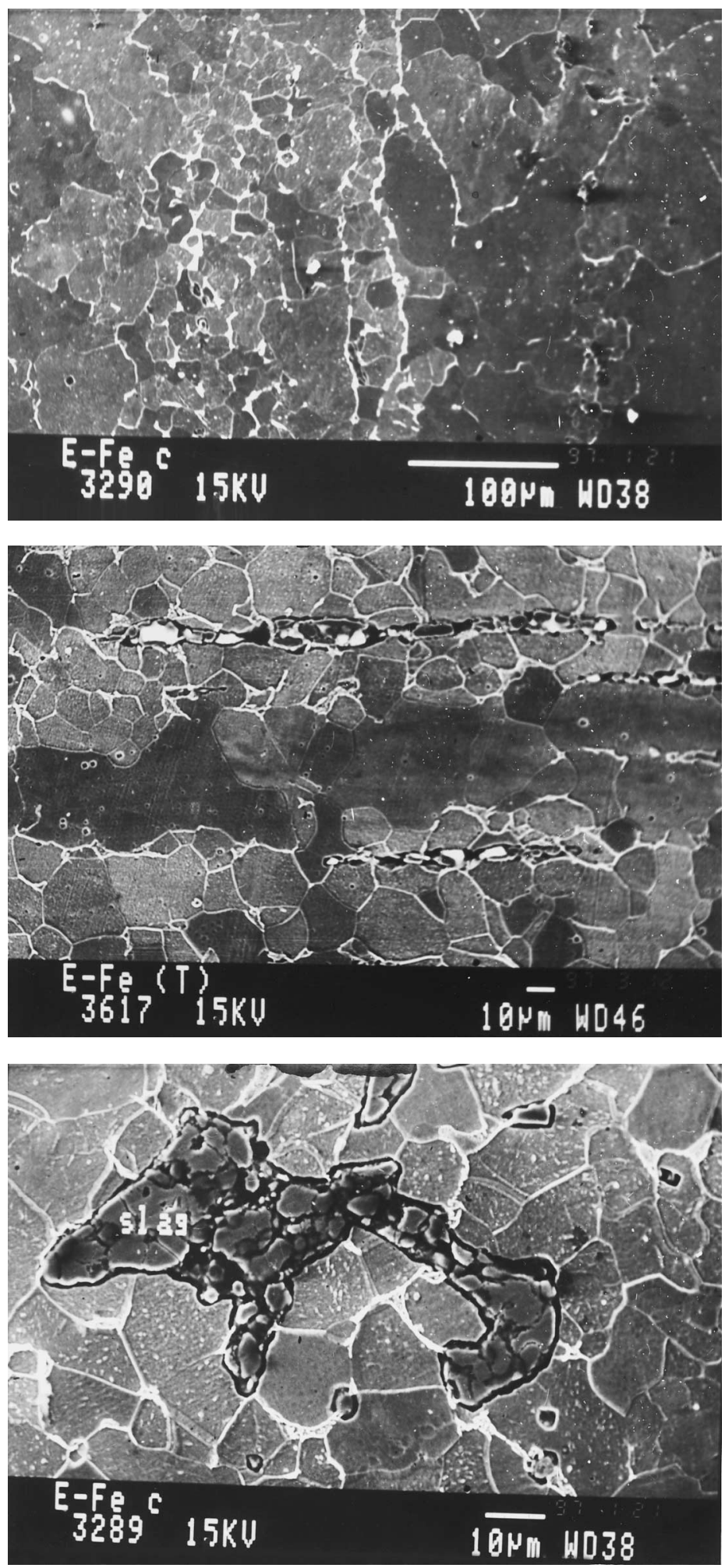

Fig. 1. SEM micrographs showing the overall non-uniform grain structure in (a) working direction, and (b) transverse section with banded second phase structure. (c) Notice the separation at the metal-slag interface. 
remove the slag formed during the extraction process. A flux was added (silica was sprinkled on the iron) so that it could combine with the unreduced $\mathrm{FeO}$ and be removed. In the process, some of the slag and some of the unreduced $\mathrm{FeO}$ invariably remained in the microstructure as these could not be completely squeezed out by hammering. Therefore, another characteristic feature of ancient Indian iron is that it contains slag dispersoids and unreduced $\mathrm{FeO} .{ }^{11-13}$ This has also been borne out by the present study.

The composition of the iron was analyzed at different locations in the structure using the EPMA. Carbon was depleted near the surface regions whereas the carbon content determined in the central regions $(\cong 0.03 \%)$ agrees with that calculated from the microstructure, using lever rule. On the other hand, the P content was higher in the surface regions whereas it was depleted in the central regions. The overall $\mathrm{P}$ content (including the $\mathrm{P}$ in metal as well as the slag) was also analyzed by wet chemical analysis and it was determined to be $0.25 \%$.

Cross-sectional microscopy of the rust scale indicated that it consisted of an adherent layer of rust (Fig. 2(a)). In some regions, there was a compact adherent inner layer with a loose outer layer (Fig. 2(b)). The $P$ content was higher at the scale metal interface (arrowed in Fig. 2(b)) and in the inner compact rust layer compared with the outer scale. However, the nature of the oxide scale could not be conclusively understood from microscopy. Therefore, it was decided to obtain information on the constituents of rust.

\section{Constituents of scale}

The nature of the rust was analyzed initially by X-ray diffraction (XRD). The XRD pattern was diffused and did not show any distinct peaks. This indicated that the major constituent(s) of rust was(were) essentially amorphous as only diffuse peaks could be obtained from the surface.

The FTIR spectrum is provided in Fig. 3. It can be noted from this figure that the presence of $\gamma-\mathrm{FeOOH}, \alpha-\mathrm{FeOOH}$ and $\delta-\mathrm{FeOOH}$ is confirmed by the appearance of peaks at $1020 \mathrm{~cm}^{-1}(\gamma-\mathrm{FeOOH}), 890 \mathrm{~cm}^{-1}(\alpha-\mathrm{FeOOH})$ and $470 \mathrm{~cm}^{-1}(\delta-\mathrm{FeOOH}) \cdot{ }^{17,18}$ Interestingly, the peak due to $\mathrm{Fe}_{3} \mathrm{O}_{4}\left(\right.$ at $580 \mathrm{~cm}^{-1}$ ) was absent indicating that either it is not present or that it's structure has been modified by doping with other ions. Moreover, $\delta-\mathrm{FeOOH}$ is the major component of the rust as the peak is of relatively larger height compared to the others. An interesting result from the FTIR spectrum was that there was a distinct signal from the phase $\mathrm{FePO}_{4} \cdot 2 \mathrm{H}_{2} \mathrm{O}$ (peak appearing at $1168 \mathrm{~cm}^{-1}$ ) and the shoulder from this phase was also identifiable. ${ }^{19}$ Therefore, the results of the FTIR study indicated that the constituents of the scale were $\gamma, \alpha$ and $\delta-\mathrm{FeOOH}$ in addition to a small amount of $\mathrm{FePO}_{4}$.

In order to further understand the nature of the rust, the Mössbauer spectrum obtained from the rust in the transmission mode was analyzed (Fig. 4). The doublet (peak 1) indicates the presence of $\gamma-\mathrm{FeOOH}, \alpha-\mathrm{FeOOH}$ and $\delta-\mathrm{FeOOH}$ in superparamagnetic form. The appearance of the doublet also indicates that it is due to to the very fine particle size of these oxyhydroxides, which confirms the amorphous nature of these phases as determined by XRD. A sextet should have appeared if these phases were crystalline. $^{20,21}$ The asymmetry in the doublet (Peak 2) suggests that the presence of one more peak with higher quadrupole splitting. This could be due to the presence of ferrous phosphate. ${ }^{20,21}$ Finally, the sextet that is obtained provided a magnetic field $\left(H_{m}\right)$ of $430 \mathrm{kOe}$ which is lower than that for magnetite $\left(\mathrm{Fe}^{3+}\right.$ in octahedral sites: $H_{m}=532 \mathrm{kOe}$, $\mathrm{Fe}^{3+}$ in tetrahedral sites: $H_{m}=493 \mathrm{kOe}$ and $\mathrm{Fe}^{3+} / \mathrm{Fe}^{2+}$ pairs in tetrahedral sites: 

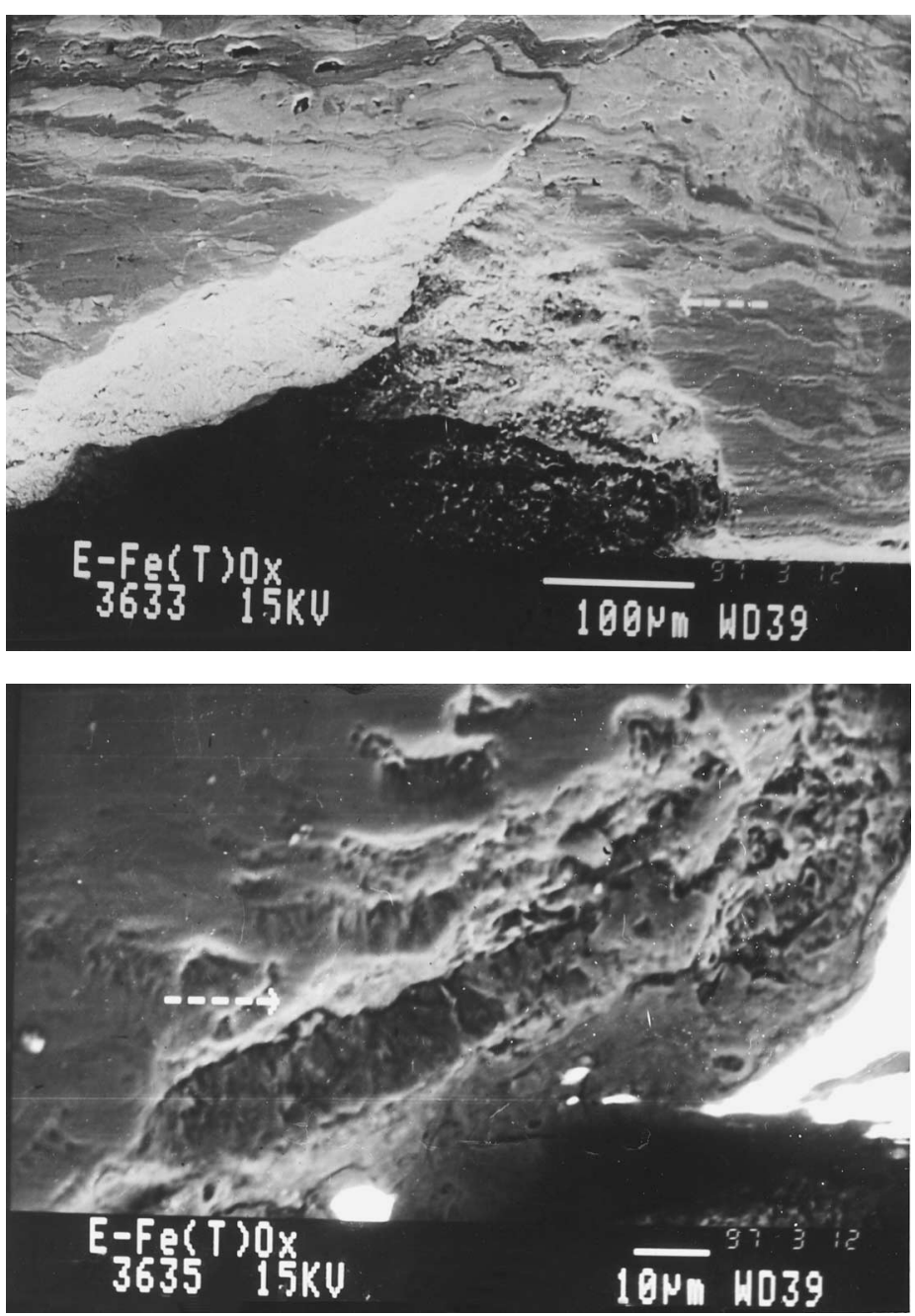

Fig. 2. SEM micrographs showing (a) the adherent nature of the rust scale and (b) compact inner adherent scale and a loose thin outer layer. The $\mathrm{P}$ content was higher at the arrowed regions.

$\left.H_{m}=471 \mathrm{kOe}^{22}\right)$. The magnetic oxide identified in the ancient Indian iron, with a magnetic field of $430 \mathrm{kOe}$, which is not reported in the literature, may be due to the incorporation of ions in the $\mathrm{Fe}_{3-x} \mathrm{O}_{4}$ lattice. Therefore, the Mössbauer study of the ancient Indian iron indicates that the rust is also composed of magnetite $\left(\mathrm{Fe}_{3-\mathrm{x}} \mathrm{O}_{4}\right)$ that is incorporated with some ions.

In summary, the rust analysis indicates that it contains, to a major extent, amorphous $\mathrm{FeOOH}$ (with the majority of it in the $\delta$ form), iron phosphates and magnetite (doped with ions).

\section{Process of protective rust formation}

The process of protective rust formation on the ancient Indian iron clamp would be outlined based on the results presented above and on available literature on the nature 


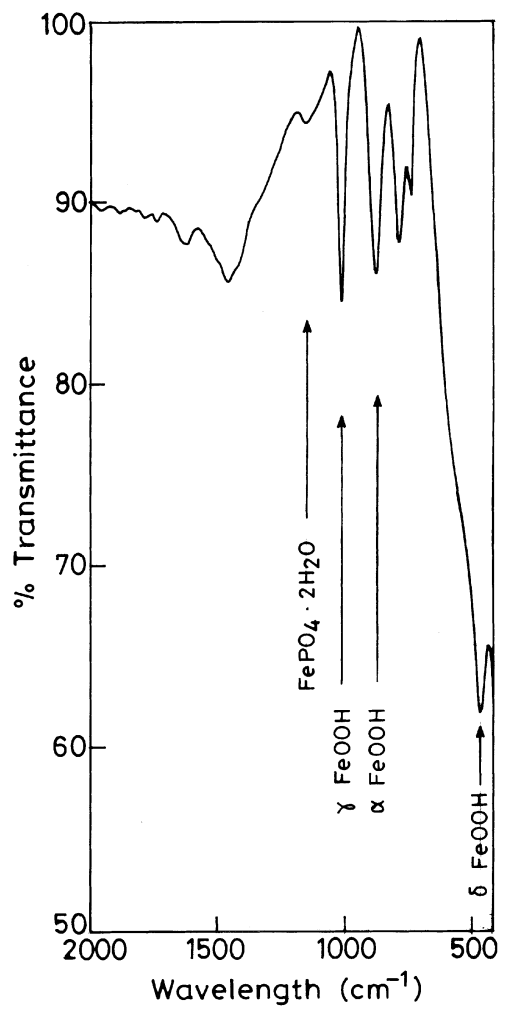

Fig. 3. FTIR spectrum of the rust from the Eran iron clamp.

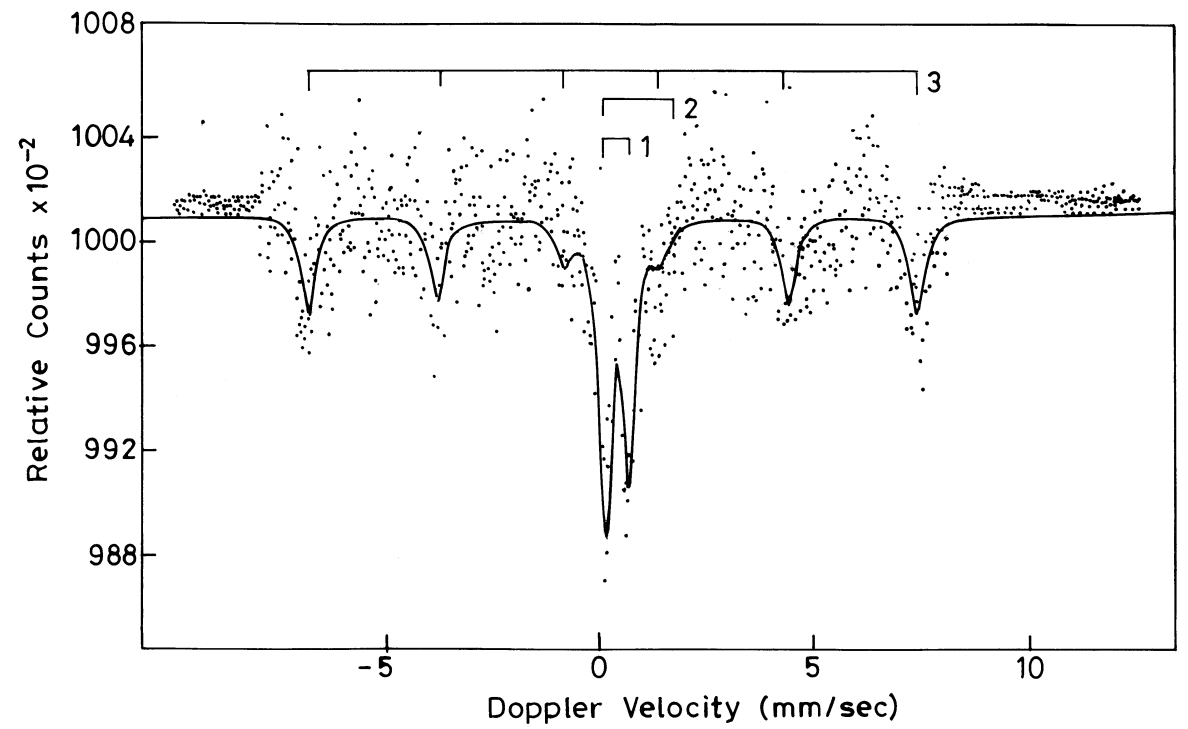

Fig. 4. Room temperature Mössbauer spectrum of the rust from the Eran iron clamp. 
of rust in weathering steels. ${ }^{17}$ The rusting of normal mild steel and weathering steel is first addressed. When iron is exposed to the environment, the first oxides that form are the oxyhydroxides of $\mathrm{Fe}$ which are oxidized from $\mathrm{Fe}(\mathrm{II})$ complexes. ${ }^{17}$ Although several different allotropic modifications of the oxyhydroxides have been proposed to form on the surface of iron on initial exposure to the environment, there are firm evidences in the literature to suggest and prove that the first oxyhydroxide to form is $\gamma-\mathrm{FeOOH}$. $^{17,20,21}$ After this forms, a part of it begins to transform to another allotropic modification $(\alpha-\mathrm{FeOOH})$ and the rust at later times is composed of both these oxyhydroxides. These oxyhydroxides are not protective against corrosion and they readily crack allowing for ingress of oxygen and moisture to reach the metal surface and cause further corrosion. ${ }^{17}$ However, with time, a part of the $\mathrm{FeOOH}$ formed transforms to magnetic oxides of iron, which are much more protective than these oxyhydroxides. ${ }^{17}$ There is also debate on the exact nature of the magnetic oxide that form on exposure of the iron to the environment. This is because the diffraction peaks of $\mathrm{Fe}_{3} \mathrm{O}_{4}$ and $\gamma-\mathrm{Fe}_{2} \mathrm{O}_{3}$ occur at the same location. However, Mössbauer studies of rust formed on steel exposed to the environment does indicate that $\mathrm{Fe}_{3} \mathrm{O}_{4}$ (more precisely to be called $\mathrm{Fe}_{3-\mathrm{x}} \mathrm{O}_{4}$ ) forms first and this is later converted to $\gamma-\mathrm{Fe}_{2} \mathrm{O}_{3} \cdot{ }^{17}$ The formation of this magnetic oxide results in protection and the oxidation (corrosion) rates decrease once these oxides form on the surface from the oxyhydroxides. In addition to $\alpha$ and $\gamma \mathrm{FeOOH}$, there can be another oxyhydroxide $\delta-\mathrm{FeOOH}$ which can form on atmospheric exposure of iron. ${ }^{17}$ It is interesting to note that $\delta-\mathrm{FeOOH}$ is generally amorphous in nature and therefore no diffraction peaks would be observed from this phase. ${ }^{17}$ In ordinary mild steels, this phase does not form as a continuous layer but rather in a discontinuous manner as it results due to dehydration-oxidation of the Fe(II) complexes. ${ }^{17}$ Therefore, the $\delta$-FeOOH that forms in ordinary mild steels is not protective in nature for these reasons. However, it is possible for this $\delta-\mathrm{FeOOH}$ to form next to the metal surface as a continuous layer in which case the steel obtains corrosion resistance, as the oxyhydroxide is also amorphous in nature. The formation of $\delta-\mathrm{FeOOH}$ as a continuous layer next to the metal surface is catalyzed by the presence of $\mathrm{P}$ (also $\mathrm{Cu}$ and $\mathrm{Cr}$ ) in the material. ${ }^{17}$ Moreover, the $\delta-\mathrm{FeOOH}$ is enriched with $\mathrm{P}$ and other elements that are added for improving atmospheric corrosion resistance like $\mathrm{Cr}$ and $\mathrm{Cu}^{17}$ The presence of this amorphous layer is the reason for the excellent corrosion resistance of the weathering steels.

In the case of ancient Indian iron, the atmospheric corrosion rate of the matrix material would be accelerated initially, in the presence of slag particles, leading to the enhancement of $\mathrm{P}$ concentration near the surface. Corrosion rate measurements (by Tafel extrapolation and weight loss methods) indicate that the short term corrosion rate of Eran iron is an order of magnitude higher than that of $0.05 \% \mathrm{C}$ mild steel in acidic environment $\left(0.05 \mathrm{~mol} / 1 \mathrm{H}_{2} \mathrm{SO}_{4}\right)$ while it is comparable in mildly alkaline environment (borate buffered solution of $\mathrm{pH}=8.23) .{ }^{15}$ It must be remembered that these measurements were obtained for complete immersion conditions, quite different from atmospheric exposure. Nevertheless, the initial corrosion of the matrix must lead to enrichment of $\mathrm{P}$ content near the surface. This is verified by EPMA analysis of the metal next to the oxide which indicated enrichment of $\mathrm{P}$ in these regions (Fig. 2). With the enhancement in the $\mathrm{P}$ concentration, the formation of $\delta-\mathrm{FeOOH}$ is catalyzed and it should form as an amorphous compact layer next to the metal surface. ${ }^{17}$ The amorphous nature of the oxide is also verified by the XRD studies. Therefore, it appears that the presence of a 
significant amount of $\mathrm{P}$ is crucial to the corrosion resistance of the ancient Indian iron. The process of passive film formation on the ancient Indian iron can be visualized as follows. Initially, the corrosion of the metal leads to the formation of $\alpha$ - and $\gamma$-FeOOH. However, the presence of slag particles accelerates the corrosion of iron thereby enhancing the $\mathrm{P}$ concentration on the surface. This enhancement of $\mathrm{P}$ on the surface catalyzes the formation of amorphous $\delta-\mathrm{FeOOH}$ as a compact layer next to the surface and this results in atmospheric corrosion resistance of ancient Indian iron. With time, conversion of this $\delta-\mathrm{FeOOH}$ to a stable form of iron oxide, i.e magnetite, is possible. ${ }^{17}$ The magnetite could be doped with ions (which is indirectly verified by Mössbauer spectroscopy) and this would further enhance the corrosion resistance of the surface film on the surface. The FTIR and Mössbauer spectra indicated the presence of iron phosphates. The presence of these phosphates would provide further corrosion resistance to the passive film by lowering ionic diffusion in the oxide and also by blocking the pores in the oxide. The enhancement of $\mathrm{P}$ on the surface leads to the precipitation of iron phosphates as the ternary Fe-P-O phase diagram indicates that they are thermodynamically stable even at $\mathrm{P}$ contents as low as $0.2 \%{ }^{23}$

\section{CONCLUSIONS}

The corrosion product formed on an ancient Indian non-corroded iron clamp was studied by X-ray diffraction, FTIR and Mössbauer spectroscopy. The iron possessed a non-uniform grain structure with dispersed second phase particles. Microscopy indicated that rust present on the surface was composed of an adherent and compact inner layer and a loose outer layer. Enrichment of $\mathrm{P}$ was observed at the metal-scale interface and in the inner rust layer. XRD indicated that the rust was amorphous in nature. The FTIR spectrum provided that the major constituents of the scale were $\alpha-, \gamma-, \delta-\mathrm{FeOOH}$ and $\mathrm{FePO}_{4} \cdot 2 \mathrm{H}_{2} \mathrm{O}$. Mössbauer studies further indicated that these constituents were present in very fine form, confirming the results obtained by XRD. The presence of a magnetic oxide with a lower field strength than that of magnetite was also identified. The process of protective rust formation on the ancient Indian iron has been elucidated based on the results of the study. Initially, the corrosion rate of the iron is high due to the presence of the slag particles which results in enhancement of the $\mathrm{P}$ content on the surface. In the presence of $\mathrm{P}$, the formation of a protective amorphous compact layer of $\delta-\mathrm{FeOOH}$ is favored and this confers corrosion resistance. The conversion of $\mathrm{FeOOH}$ to magnetite is also indicated and this would further improve the corrosion resistance. Another factor aiding corrosion resistance is the formation of iron phosphates which would lower the rate of corrosion. A similar mechanism must be responsible for the corrosion resistance of the Delhi iron pillar.

Acknowledgements - The authors gratefully acknowledge the co-operation of the Archaeological Survey of India. The authors also thank Professor G.N. Mathur, Director, Defense Materials and Stores Research Establishment (DMSRDE), Kanpur 208 013, India, for permission to conduct the experiments and Dr. R.K. Nigam, Head, Electrochemistry and Corrosion Division, DMSRDE, for fruitful discussions.

\section{REFERENCES}

1. Hudson, J.C. The Delhi Iron Pillar Nature, 1953, 172, 499.

2. Wranglen, G. The Rustless Iron Pillar at Delhi Corrosion Science, 1970, 10, 761. 
3. Bardgett, W.E. and Stanners, J.F., The Delhi Iron Pillar-A Study of the Corrosion Aspects, J. Iron and Steel Inst., 210, 3 (1963) and NML Technical J., 5, 24 (1963).

4. Hadfield, R. Discussion on Friend and Thorneycraft's paper on Ancient Iron J. Iron and Steel Inst., 1925, 112, 233.

5. Ghosh, M. K. The Delhi Iron Pillar and Its Iron NML Technical J., 1963, 5, 31.

6. Balasubramaniam, R. Studies on the Corrosion Resistance of the Delhi Iron Pillar NML Technical J., 1995, 37, 123.

7. Balasubramaniam, R. Mixed Potential Theory Analysis of the Corrosion Resistance of the Delhi Iron Pillar Trans. Indian. Inst. Metals, 1997, 50, 23.

8. Evans, U.R., The Corrosion and Oxidation of Metals, First Supplementary Volume, Edward Arnold, London, p. 191-192 (1968).

9. Rosenhain, W., Physical Metallurgy, Constable, London, p. 329 (1915).

10. Herrero, A., de Zubiria, M. The Phenomenon of Corrosion of Iron and Steel J. Iron and Steel Inst., 1928, 118, 109.

11. Prakash, B. Metallurgy of Iron and Steel Making and Blacksmithy in Ancient India Ind. J. Hist. Sci., 1991, 26, 351 .

12. Prakash, B., Tripathi, V. Iron Technology in Ancient India Metals and Materials, 1986, 2, 568.

13. Prakash, B. Metallurgy in India Through the Ages Bulletin of Metal Museum, 1983, 8, 23.

14. Brown, P., Indian Architecture (Buddhist and Hindu Periods), D.P. Taraporevala and Sons, Bombay, Seventh Reprint, p. 11-49 (1976).

15. Puri, V., Balasubramaniam, R., Ramesh Kumar, A.V. Corrosion Behaviour of Ancient 1500-year old Gupta Iron Bull. Metals. Museum., 1997, 28(II), 1.

16. Tripathi, R.S., History of Ancient India, Motilal Banarsidass Publishers, New Delhi, p. 252-253 (1992).

17. Misawa, T., Kyuno, T., Suetaka, W., Shimodaira, S. The Mechanism of Atmospheric Rusting and the Effect of $\mathrm{Cu}$ and $\mathrm{P}$ on the Rust Formation of Low Alloy Steels Corrosion Science, 1971, 11, 35.

18. Music, S., Gotoc, M., Popovic, S. $X$ Ray Diffraction and Fourier Transform Infra Red Analysis of the Rust Formed by the Corrosion of Steel in Aqueous Solutions J. Mater. Sci., 1993, 28, 5744.

19. IR Spectra of Inorganic Compounds, (eds. R.A. Nyquist and R.A. Kagel), Academic Press, New York, p. 173 (1971).

20. Leidheiser, H., Music, S. The Atmospheric Corrosion of Iron as Studied by Mössbauer Spectroscopy Corrosion Science, 1982, 22, 1089.

21. Stratmann, M., Hoffmann, K. Insitu Mössbauer Spectroscopic Study of Reactions within Rust Layers Corrosion Science, 1989, 29, 1329.

22. Niomura, K., Ujihira, Y. Analysis of Oxide Layers on Stainless Steel (304 and 316) by Conversion Electron Mössbauer Spectrometry J. Mater. Sci., 1990, 25, 1745.

23. Raghavan, V., Phase Diagrams of Ternary Iron Alloys, Indian Institute of Metals, Calcutta, p. 138-140 (1988). 